\title{
Offence or Defence? Approach and Avoid Goals in the Multi-Agency Emergency Response to a Simulated Terrorism Attack
}

\begin{abstract}
When operating in multi-team settings it is important that goals are cohesive between team members, especially in high-stakes, risky and uncertain environments. This paper explored goal consistency during a multi-team emergency response simulation. A total of $n=50$ commanders from the UK Police Services, Fire and Rescue Services and Ambulance Services took part in a simulated terrorism exercise, split into $n=13$ teams. Each team responded to the same simulated terrorist event, which was based on a 'Marauding Terrorist Firearms Attack’ (MTFA) at a city centre train station. Data were collected using electronically time-stamped 'decision logs’ and post-incident questionnaires that measured team members' self-reported goals. Goals that were 'attack' focussed (e.g. 'treat patients') were coded as ‘approach' (i.e. focussed on achieving positive outcomes) and goals that were ‘defence’ focussed (e.g. protect emergency responders) were coded as ‘avoid’ (i.e. focussed on avoiding negative outcomes). It emerged that different agencies prioritised different goal types; Fire commanders initially prioritised avoid goals but then increased approach orientations, Ambulance commanders were consistently approach oriented, and Police commanders showed goal conflict (tensions between adopting approach and avoid goals). Despite goal differences, participants rated that their inter-agency goals were consistent in a post-scenario questionnaire, suggesting that commanders were unaware of the nuanced differences between their agency-specific objectives. At the multi-team level, teams who predominantly held attack/approach goals were significantly faster at decision logging early in the incident; yet defend/avoid teams were faster at decision logging later into the incident. Implications for multi-team coordination are discussed.
\end{abstract}

Keywords: Decision making; teams; goals; emergency services; major incident; terrorism 


\section{Practitioner Points}

- The 'save life' goal in multi-team emergency response settings is vague and open to interpretation. This can impede coordination when agencies assume that they are working towards the same 'save life' goal, but are actually focussed on different and role-specific objectives with regards to how they'll achieve it.

- A joint decision model that helps to clarify agency-specific tactical priorities may be more useful in multi-team contexts than one that uses ambiguous and abstract (i.e. 'save life') inter-agency goals.

- A focus on achieving positive outcomes (attack/approach goal; e.g. 'treat patients') can speed up decision making during the early stages of an incident, but when the situation becomes more complex and dynamic, then a focus on avoiding negative outcomes (defend/avoid goal; e.g. protect emergency responders from harm) might lead to faster action.

- When responding to complex emergencies, practitioners should focus on satisficing to achieve 'least-worst' outcomes rather trying to maximise gains. 


\section{Introduction}

Critical incidents are extreme environments wherein individuals and teams must make high-consequence decisions, whilst operating under dynamic and uncertain conditions (Millitello, Sushereba, Branlat, Bean \& Finmore, 2015). They are unpredictable and include severe risk and threat (Orasanu \& Liberman, 2011), are characterised by missing and conflicting information (Bharosa, Lee \& Janssen, 2010) and involve extreme time pressure (Chen, Sharman, Rao \& Upadhyaya, 2008). They place significant demands on the physical, psychological and interpersonal skills of the decision maker (Orasanu \& Lierberman, 2011), which can lead to cognitive overload, stress, force errors and derail plans of action (Paton \& Flin, 1999; van den Heuvel, Alison \& Power, 2014).

Not only are emergencies characterised by ambient (i.e. relating to the inhospitable environment) and task (i.e. relating to the incident characteristics) extremes, but they also include social extremes (i.e. relating to life-threatening reliance on one’s team) (Orasanu \& Lieberman, 2011). They involve 'multi-team systems' in which “two or more teams interface directly and interdependently in response to environmental contingencies toward the accomplishment of collective goals” (Marks, Mathieu \& Zaccaro, 2001, p. 290). Social extremes can arise at both the intra-agency level, within an emergency service team (e.g. ambulance service), and at the inter-agency (between-agency) level (e.g. between the fire, police and/or ambulance services). A post-incident review of the response to widespread flooding in the UK in 2007 identified that social extremes, such as confusion about roles and responsibilities and a lack of overall leadership, contributed to significant delays in responding (Pitt, 2008). Furthermore, poor prioritisation of relevant information was identified as a reason for slow action during the response to the 2010 earthquake in Haiti (Patrick, 2011). One way to try and improve multi-team coordination is through the identification of clear goals that clarify the team's shared superordinate objectives (Marks, et al., 2001; Mathieu, Heffner, Goodwin, Salas \& Cannon-Bowers, 2000). Problem solving in teams relies upon effective communication, which includes information sharing, communicating clear routes to deploy specific action and an ability to reflect and learn about the response to a task (Orasanu, 1993). Teams need to communicate in iterative cycles, to develop a shared and updated mental model of the incident, which will help them to work collaboratively towards shared goals (Hutchins \& Kendall, 2011). 
The inherently uncertain characteristics of emergencies can threaten the ability of teams to operate in a clear, goal-directed manner. The high levels of stress associated with emergency incidents can exceed the cognitive capacity of individuals to manage stress levels whilst also attempting to self-regulate their decision making towards the achievement of collective goals (Drach-Zahavy \& Erez, 1997). When placed under conditions of high-stress, individuals abandon collective goals and instead focus on the most important 'sacred values' of their own agency. It was found during a simulated emergency response to a major aeroplane crash that when tasks lacked direction, were non-time bounded, and involved two or more agencies, that teams focussed on intra-agency information seeking rather than collaborative communication and action (Alison, Power, van den Heuvel, Humann, Palasinksi \& Crego, 2015). The more complex the incident, the less collaborative the multiteam response.

For the present study, we took an exploratory approach to investigate how the UK emergency services used goals when operating in complex, multi-team settings. Specifically, we explored how similarly aligned participants' goals were when operating in a multi-team environment. Are, for example, commanders' goals consistent within teams as well as across teams? Multi-team goals should be cohesive during emergencies; as single response agency performance is reliant upon effective coordination with other response agencies. For example, in a multi-vehicle traffic collision on a busy motorway, the Ambulance Service will be reliant upon the Fire and Rescue Service to free trapped casualties in order to treat patients; the Fire and Rescue Service will be unable to perform extrications without assistance from the Police Service to close lanes of the motorway to allow for safe working; and the Police Service need to be kept informed on incident progress in order to facilitate effective traffic management and ensure normality is restored as quickly as possible. All of these priorities orient around the ultimate goal of 'saving life', with each agency being reliant upon the performance of other agencies in order to achieve this collective goal. Should one agency prioritise their individual goals with little regard for other agencies (e.g. police reopen the motorway due to pressures to free up traffic), then this will limit the capacity for other agencies to perform.

We collected data from a simulated, multi-team training exercise of a 'Marauding Terrorist Firearms Attack’ (MTFA) (i.e. a moving team of terrorists attacking civilians with firearms). MTFA incidents are rare, but especially challenging due to the high risk of mass civilian and responder casualties, the rapid and fast-moving pace of the attack, the uncertainty 
of who the terrorists are, or where further attacks may take place, and the inability to contain the scene due to the 'marauding' nature of the incident. Real-world examples of such attacks include the Mumbai bombings of 2008, the 2013 Westgate Shopping Mall attacks in Nairobi, where tension, poor coordination and infighting between authorities including the police and the military led to severe delays in action, and the recent and tragic events that took place in Paris in November 2015, which resulted in 166, 67 and 130 civilian deaths respectively. The simulation in the present study did not specify who the terrorists were, in order to align with the ambiguous nature of such events.

This paper primarily sought to ask whether the self-reported goals of commanders who were responding to this incident were consistent across the three emergency services. This was in response to recent changes to multi-agency emergency guidance the UK, under the 'Joint Emergency Services Interoperability Programme' (JESIP, 2013), which has sought to increase the tendency for emergency response agencies to operate cohesively as a matter of routine; specifically, by encouraging 'joint' decision making. Although 'joint' decision making is theoretically desirable to help coordinate action, this study sought to explore whether the goals between the three services are in fact consistent with one another. If goals differ, this questions whether 'joint' decision making is either achievable or desirable. Each emergency service has its own distinct set of capabilities and role-specific objectives and so, rather than focussing on vague macro-level goals (e.g. 'save life'), it might be more useful to identify discrete, agency-specific objectives. A greater awareness of agency-specific objectives, as opposed to vague superordinate end-points, could be more useful for decision making across a distributed multi-team network. Data was also explored at an inter-team level to see how different types of goals influenced the time it took to log a joint decision. Specifically, do 'attack' (approach) goals, which focus on achieving positive outcomes (e.g. save life/treat patients) lead to faster choices than 'defence' (avoid) goals, which focus on avoiding negative outcomes (e.g. protect emergency responders)? We had two research questions:

RQ1: Are the goals of the Police, Fire and Rescue and Ambulance Services aligned when responding to a simulated terrorist incident?

RQ2: How does goal orientation interact with the time it takes to make a decision?

\section{Goal and Objective settings in teams}


Decision making in organisational settings is driven by goals (Yates, 2003). Goals act as motivational markers that direct human behaviour towards purposeful outcomes (Locke \& Latham, 1990). In order for goals to be effective, it is important that they are specific rather than abstract or vague (Locke \& Latham, 1990). For example, the goal to 'respond to the emergency’ is a vague goal with no obvious behavioural link to how to achieve this goal; whereas the goal to 'identify the number of casualties' is a concrete goal that can guide behaviour. In order to clarify the difference between abstract and concrete goals, 'goals' are hereby defined as vague, abstract and broad (e.g. 'save life') whereas 'objectives' are defined as concrete, narrow and measurable (e.g. identify number of casualties). Individuals might hold different objectives that are oriented around achieving the same end-goal ${ }^{1}$.

In order to translate goal-directed intentions into action, individuals need clear ‘implementation intentions’ (Gollwitzer, 1993; 1999). Implementation intentions are the tactical mechanisms that guide how individuals respond to situations (i.e. 'if situation $\mathrm{Y}$ happens, I will do X') and create teleological end points. Having clear implementation intentions increases the efficiency and likelihood of attaining a goal. A paramedic might hold a goal to 'save saveable life', yet their implementation intentions could differ depending upon the perceived criticality of the patient. If the casualty is in a critical condition, they might implement a fast intervention (e.g. quickly triage the patient and get them to hospital); whereas if the patient is more stable, they might perform slower, yet safer, procedures by working on the casualty at the scene. Goals alone are not enough to facilitate behaviour; commanders must also hold implementation intentions derived from knowledge about which behaviours will most likely lead to goal attainment.

Although goal-setting can have a positive impact on decision making by directing behaviour, goals can impede decision making if they are ambiguous, contradictory or vague. Ambiguous or abstract goals (e.g. 'do your best') can decrease performance as such goals are not anchored to behavioural options, nor information about how to 'do one’s best' (Locke \& Latham, 1990; 2002). Alternatively, overly specific (often context bound) goals or objectives can degrade choice if the problem environment is complex, as decision makers experience cognitive overload and excessive stress (Drach-Zahavy \& Erez, 1997). Overtly specific goals can also distract individuals from the consideration of alternative options, leading to selective processing and ‘tunnel vision’ (Drach-Zahavy \& Somech, 1999).

\footnotetext{
${ }^{1}$ Thanks to a reviewer for illuminating this distinction.
} 
The ability to achieve one's goal can be influenced by how the goal is phrased or oriented. When goals are avoidance oriented (e.g. avoid performing poorly), they have the potential to degrade performance or lead to behavioural inhibition. This occurs as decision makers are focussed on the potentially negative consequences that might arise from their behaviour and so struggle to perform or commit to an action (Corr, DeYoung \& McNaughton, 2013). In a simulated police investigation, officers' struggled to discriminate between relevant and irrelevant information and performed more poorly when they were concerned about being held to account to poor decision making (i.e. avoidance goal) (Waring, Alison, Cunningham \& Whitfield, 2013). Officers performed worse as they were preoccupied by 'defensive' goals to protect themselves (i.e. avoiding negative accountability). The 'approach-avoidance' distinction has been explored at the behavioural level, where the experience of positive emotions induces movement towards a stimulus (approach); whereas the experience of negative emotions induces movement away from a stimulus (avoid) (Carver \& White, 1994). Neurobiological research has suggested that approach and avoid behaviour is linked to activation in the septo-hippocampul region of the brain (Gray \& McNaughton, 2000) and that chronic activation of these areas can influence the tendency to show approach or avoidance behaviours (Carver \& White, 1994). Alternatively, from a goal-setting perspective, approach goals reflect a desire achieve positive outcomes (e.g. 'treat casualties'); whereas avoid goals are associated the desire to avoid negative outcomes (i.e. 'prevent the emergency escalating') (Bossuyt, Moors \& DeHouwer, 2014; Elliot, 2006; Elliot, Eder \& Harmon-Jones, 2013). In the context of emergency responding, this distinction between goal types reflects the difference between the goal to 'attack' (approach) the situation to achieve positive outcomes, versus the goal to 'defend' (avoid) making the situation worse.

Goal-setting in teams adds a further layer of complexity due to the potential for goal conflict between personal, organisational and collective inter-organisational goals (Locke \& Latham, 2006; Seijts \& Latham, 2000). The desire to achieve a goal in organisational settings is associated with one's level of investment in the team's goals (Yearta, Maitlis \& Briner, 1995). Feelings of ‘psychological ownership’ (Edmondson, 1999) can facilitate goal accomplishment as individuals feel committed to and supportive of goals. This is relevant to emergency responding as commanders must not only consider their personal goals, but also their professional within-team (i.e. individual agency) and between team (i.e. multi-agency) goals (Marks, et al., 2001; Mathieu, et al., 2000; Millward, Banks \& Riga, 2010). A lack of commitment to team goals reduces feelings of investment and can derail action. This might 
be especially problematic in complex domains, where 'hyper-competition' between subteams can arise (Brown, Crawford \& Darongkamas, 2000; He, Baruch and Lin 2014). This occurs when intra-team members favour in-group goals over collective inter-team goals and so will prioritise the goals of their own team. Alison et al., (2015) found that emergency responders prioritised intra-agency information seeking over inter-agency information sharing when incident demands increased. Thus, although clear and concrete goals can facilitate decision making performance (Locke \& Latham, 1990; 2006), when goals are used inappropriately, by being too abstract, too specific or in direct conflict with competing personal or intra-team goals, then decision processing can derail.

\section{Aims}

The UK government have sought to increase 'joint' working between the blue lights services in the UK. The 'Joint Doctrine’ published by JESIP (2013) has outlined the need for increased 'interoperability' during emergencies, which relates to five principles: (i) ensuring co-location at scene; (ii) unambiguous communications; (iii) better coordination of efforts; (iv) joint understanding of risk; and (v) a shared situational awareness. In order to improve interoperability, JESIP have developed the ‘joint decision model’ (JDM) to ensure commanders "bring together the available information, reconcile objectives and then make effective decisions together” (p.12, JESIP, 2013). It identifies two common goals for emergency responders at the centre of the model: to 'save life' and 'reduce harm'. Theoretically, the identification of these goals should help to direct joint action. However, the usefulness of these goals is contingent upon commanders sharing a common interpretation of what these goals mean for behaviour. What does 'save life' and 'reduce harm' actually mean in practice? Are these goals reliably useful across all types of emergency incident? And is the interpretation of these goals consistent across response agencies, or might different agencies interpret them in different ways? We explored how different agencies used goals when responding to a simulated MTFA exercise. Specifically, we were interested in how consistent goals were between different response agencies agencies. We also explored how multi-team (approach/avoidance) goal orientations interacted with the time it took teams to take collective action.

\section{Methodology}

Data were collected from an Immersive Simulated Learning Environment (ISLE) to explore the real-time decision making of emergency commanders responding to a simulated 
multi-team terrorist incident (see Alison, van den Heuvel, Waring, Power, Long, O’Hara \& Crego, 2013). The study was conducted using 'Hydra', a computer based ISLE where participants are provided with audio, video and textual information about an unfolding incident. Information is fed to participants in real-time and dynamically changes in relation to the decisions made by delegates. Delegates are asked to log their decisions in an electronic 'decision log', which is visible to the exercise facilitators in the control room, who may then adapt the flow of the unfolding incident accordingly. Although 'Hydra' is traditionally used to train decision making skills in complex and high-stakes environments, it was adapted in this study to facilitate data collection. The simulation was designed in close collaboration with subject matter experts (SME) from each of the blue lights agencies in order to provide a training benefit to the delegates who participated. Appendix A provides a guide for conducting multi-method data collection with practitioners, outlining four key stages: (i) Conception: identifying research and training needs; (ii) Development: creating scenario and measurement tools; (iii) Testing: pilot testing and actual study/training; and (iv) Feedback: practitioner and academic outputs. The context of an MTFA incident was used as this complemented recent classroom training that participants had received on 'joint decision making' in line with JESIP. MTFAs are also a national priority for training in the UK to ensure that responders are resilient against terror threats, which has been made more salient since the recent devastation in Paris in November 2015.

\section{Participants}

A total of $n=50$ commanders participated in the study, who were split into $n=13$ teams. Each team completed the same simulation. Participants were qualified incident commanders from the Police Service $(\mathrm{n}=17)$, Fire and Rescue Service $(\mathrm{n}=22)$ and Ambulance Service $(n=11)$. They were recruited via email by the subject matter experts (SMEs) involved in the project. The majority of participants were male $(n=46)$ and aged between $41-50$ years $(n=37)$. All participants were experienced and their length of service ranged from eight to 35 years, with a mean average of 24.03 years. The aim was to have at least one representative from each agency present during each simulation; however, occasionally representatives who had agreed to participate became unavailable at the last minute because they had to respond to an unanticipated real-life incident. Thus, at times $(n=3)$, only two out of the three agencies had a representative present in the simulation. Although this is an acknowledged, albeit anticipated, limitation due to the nature of the participants' job, data were retained for these three groups in the overall analysis. The reasons for doing so are threefold: firstly, the sample size for this 
study was small due to access difficulties when working with highly skilled professionals, so it was decided that data loss would have a larger negative impact on research conclusions than retaining data; secondly, a key focus of this study was on goal orientations of agency members, which was recorded at the individual participant level, and so this data was still valid in these three groups; and thirdly, whenever an agency representative was absent in the simulation, the multi-team context was retained as an expert SME in the control room 'simulated' the missing agency by providing information and decisions on behalf of the absent agency through the computer’s ‘communicator’ system.

\section{Data Collection: Hydra}

Hydra is an ISLE that has been used extensively to train practitioners in high-stakes decision making in a variety of domains, including major incident management, child protection and national security (Hydra Foundation, 2015). It is typically used as an organisational training tool, allowing 'trainees' to role play challenging decisions in an immersive and realistic, yet simulated and safe, environment. Hydra can train both organisationally-specific skills (e.g. major incident response) and more general skills relating to team management (e.g. human resources issues). Importantly, not only can Hydra facilitate practitioner training, but it creates a data rich environment from which it is possible to conduct research (Alison, et al., 2013); for example, by analysing the data that is digitally recorded during the simulation (e.g. decision logs, audio recordings). Previously, Hydra has been used for research in terms of providing secondary data that was collected during training events (e.g. Alison, et al., 2015). The present study was unique, using Hydra as a platform to specifically design a simulation for both training and research (see Appendix A for a guide).

\section{Using Hydra as a simulation platform for Naturalistic Decision Making research}

'Naturalistic Decision Making' (NDM) research seeks to understand how people operate and cope with decision problems 'in the wild' (Gore, Banks, Millward \& Kyraikidou, 2006; McAndrew \& Gore, 2012). Simulations offer a fruitful method for collecting NDM data in high fidelity environments, whilst maintaining experimental control. The general process of a running a simulation involves two teams of people: (i) the delegates, who are participating in the simulation as decision makers; and (ii) the facilitators, who are located in an external control room to monitor simulation progress. In the case of Hydra, delegates are placed inside a 'syndicate room' (Figure 1), where they receive information relating to the unfolding incident. Hydra is a team-based simulation and so groups can be intra-team (e.g. all 
Police Service) or multi-team (i.e. Police, Fire and Ambulance Service). Unlike virtual reality simulations, which use headsets and haptic sensors to create visually immersive environments, Hydra delegates are provided with information via audio, video and textual messages that are transmitted over a large projected screen (Figure 1). The focus is to create a psychologically immersive environment, rather than prioritise visual immersion. Delegates can also be given additional real-world tools in the syndicate room, such as maps and laptop computers. Delegates interact with the simulation by using a computer, where they are able to access their 'decision log' (to log actions) and 'communicator' (to ask questions to the control room).

The facilitator team in a Hydra simulation, which can include SMEs, trainers and researchers, are located in the 'control room'. This room contains numerous computer screens that are used to monitor the behaviour in the syndicate room. As demonstrated in Figure 2, it is possible to run multiple syndicate rooms at once depending upon the objectives of the exercise. Facilitators have responsibility for 'firing' information into the syndicate room via the computer. Generally, a 'timeline' is used to guide this process (Table 1), which roughly outlines the narrative order of injects, although this can change in response to the decisions made by the delegates. The live monitoring of delegates in the room, via CCTV and audio, helps improve the realism of the exercise, as information feeds can be prepared in advance to delegates submitting their decisions on the log and new challenges can be created 'in vivo' based on performance. For example, in the current study, the Ambulance Service SME felt that their delegates could be challenged more. A new information feed was prepared 'in vivo' to ask the Ambulance Service delegate about their 'patient extrication method' (i.e. how they were going to treat casualties in the high-risk 'warm' zone). Following the simulation, a 'debrief' is held, where SMEs dissect the decision making of the delegates in an open, informal setting.

\section{The simulation timeline}

It is important to identify both research and training needs when designing a simulation to be used for research and training. For this study, research goals were to explore commandlevel decision making in a multi-team environment where it would be possible to unpack choices using decision logs and post-simulation questionnaires. It was important to replicate the incident across groups in order to compare groups, and so the timeline required a linear structure, albeit with the potential for additional information when required (Table 1). 
Training goals were to create a simulation to ground previous classroom training on the JESIP interoperability programme. An MTFA scenario was chosen as it would challenge commanders' abilities to make 'joint' choices because there is no clear authority (or agency 'primacy') with regards to many of the required decisions (e.g. whether to commit staff into the risk area).

The scenario timeline for this study is outlined in Table 1. Two key injects were inserted to challenge decision making as identified by SMEs. Firstly, the 'zoning task' (inject 2) asked commanders to make a joint decision on where to place the 'hot', 'warm' and 'cold' zones. This is a procedure used by the emergency services for identifying risk during an ongoing incident. For a terrorist incident, the 'hot' zone is the area in which the terrorists are operating and only armed-response-team police officers are allowed to in this zone. The 'warm' zone is the area that the terrorists have either already been or have the potential to (re)enter, where only specialist trained emergency workers from the three services may operate. This means that staff numbers are limited and civilians within the warm zone must be evacuated immediately. The cold zone is the area outside the incident where there is little or no risk to responders and civilians. As such casualty triage centres are usually located here. Inject 2 asked delegates to make a joint decision to classify these zones to facilitate safe working for their teams, as would be expected in a real-life incident.

The second key inject in the scenario was the 'non-specialist staff at rendezvous point (RVP)' decision (inject 7). By this point of the exercise, resources were depleted (due to an additional fire inside the train station) and civilians were bleeding and dying on the concourse (which by now should have been re-zoned as a 'warm' zone as the terrorists had moved to the underground). Delegates had to decide whether to break protocol and allow non-specialist staff (who had lifesaving skills but lacked specialist training and appropriate personal protective equipment (PPE) for firearms) to operate on a voluntary basis in the area and help with casualty rescue and treatment; or whether to refuse them access this area in order to protect emergency workers and continue to operate with stretched resources whilst casualties worsened and fatalities grew. As this was a 'wicked problem', with no right or wrong answer, the delegates received an angry message from the Fire and Rescue Chief regardless of their decision (inject $8 \mathrm{a} / \mathrm{b}$ ). This prompted them to justify their actions and reflect on their rationale.

\section{Procedure}


Prior to entering the syndicate room, participants were provided with limited information in order replicate a real-world unanticipated major incident. On arrival, delegates were introduced to one another, the SME team, the research team and their loggist, who typed and logged decision on behalf of the team. The exercise began by seating delegates in a room that was external to the Hydra suite. They were provided with a piece of paper, which outlined agency-specific information with regards to initial reports of the incident ("three gunmen reported to have opened gun fire at a city centre train station”) and available resources ("one armed response vehicle is en-route with an ETA [estimated time of arrival] of 7 minutes”). Whilst reading this information, they were asked to imagine that they were 'enroute' to the incident with an ETA of five minutes. Participants were left alone during these five minutes, whilst the 'facilitator team' set up the control room. The facilitator team consisted of one SME from each agency and two researchers who operated exercise control. After five minutes, participants were moved into the syndicate room and received their initial inject (Table 1). The syndicate room contained plain paper and three maps of the train station: one close up of the station concourse; one of the station and immediate surrounding area; and another aerial view of the station and wider surrounding area. The exercise was monitored by SMEs, who advised when the next inject should be provided (i.e. when they felt that the group had effectively responded by asking questions and logging decisions). Variability in this process was reduced by using the same SMEs across the 13 exercises. SMEs also helped to answer agency-specific questions by, for example, providing local information on where the British Transport Police headquarters was located in the region that the exercise took place.

\section{Materials}

Decision Log. Participants logged their decisions using an electronic decision log. This was via a 'loggist' who was instructed by the team to log a decision when the group had collectively made a decision. The loggist also sent information requests to the control room when asked to by participants (e.g. ETA of additional resources), however these messages were 'communications' rather than 'decisions'. This study was only interested in logged joint team decisions. The decision log had two open-text boxes: (i) one for their 'decision'; and (ii) one for their 'rationale'. Logs were time stamped and so it was possible to identify how long it took a team to log a joint choice after they received an inject. The two decisions of interest that were identified by SMEs as being challenging to interoperability (i.e. zoning decision; non-specialist staff at RVP decision) were used to measure the time lag between the 
information inject (i.e. to make a decision on zoning and log it on the computer) and the time the team logged their choice (e.g. zones are x, y, z).

Questionnaire. Participants completed a questionnaire at the end of the simulation. They were asked to: "List in order your main three goals during the scenario (from most important)”. They were also asked to rank their level of agreement from one (strongly disagree) to seven (strongly agree) with the statement: "Goals between agencies were inconsistent”. Two questions were used to 'validate' the simulation for 'realism' and 'risk'. Participants' mean score for 'realism' fell in the 'agree' range $(M=5.90, S D=.99)$ with no significant differences between agencies, $F(2,49)=.610, p=.548$, and 'high-risk' fell within the range of 'agree' to 'strongly agree' $(M=6.14, S D=1.06)$ with no significant differences between agencies, $F(2,49)=1.946, p=.154$. This suggests participants found the simulation high-risk and realistic.

\section{Results}

\section{Main goals}

Participants were asked to: "List in order your main three goals from the scenario (from most important)". An inductive, bottom-up analysis of responses revealed six types of goal, which were coded by the authors and discussed to reach mutual agreement when codes differed (Table 2). Goals that did not fit into a common theme were left uncoded (e.g. "test knowledge of procedures”). Taken collectively, the most commonly identified goal by participants was to 'save life/treat patients', followed by 'protect emergency responders from harm', 'establish shared situational awareness/joint working', 'protect the public from further harm', 'locate/neutralise threat and 'prepare for post-incident demands' (Figure 3).

It emerged that participants identified different types of goals depending upon their agency membership (Figure 3). The most commonly cited goal by Police commanders was to 'locate/neutralise threat', followed by 'protect the public from further harm', 'protect emergency responders from harm', 'save life/treat patients', 'established shared situational awareness/joint working' and 'prepare for post-incident demands'. Fire and Rescue participants' most common goal was to 'save life/treat patients', followed by 'protect emergency responders from harm', 'establish shared situational awareness/joint working', 'protect the public from further harm' and 'prepare for post-incident demands'. Likewise, 'save life/treat patients' was the most common goal for Ambulance participants, followed by 
'establish shared situational awareness/joint working', 'protect emergency responders from harm' and 'protect the public from further harm'.

\section{‘Approach’ (attack) versus ‘Avoid’ (defend) Goals}

The six goal types identified by participants were additionally coded according to approach-avoid orientation (Corr et al. 2013), using the same process of mutual agreement as above. Approach goals were linked to 'attack' motivations and focussed on taking action that might have a positive impact on the situation (e.g. 'treat patients'); avoid goals were linked to 'defend' motivations and focussed on taking action that would prevent a negative impact on the situation (e.g. 'protect emergency responders') (Table 3). There was a relatively even split between the prevalence of approach and avoidance goals overall, as 57\% of all participants' goals were approach oriented and 43\% avoidant. Approach goals included 'save life/treat patients' (positive impact on casualties), 'establish shared situation awareness' (positive impact on shared intelligence) and 'locate/neutralise threat' (positive impact on threat). Avoid goals included 'protect emergency responders' (prevent negative impact on responder safety), 'protect the public from harm' (prevent negative impact on wider public) and 'prepare for post-incident demands' (prevent negative impact on post-incident investigation).

\section{Comparison of goal orientation between agencies}

Data were explored for differences between agencies in terms of their goal orientation. Overall, 52.2\% of Police participants' goals were approach oriented, 53.2\% of Fire and Rescue participants' goals were approach oriented and 73.3\% of Ambulance participants' goals were approach oriented. This suggests that whereas both Police and Fire participants had fairly even proportions of approach to avoid goals, Ambulance participants were predominantly approach oriented. A Pearson's chi-square test found a significant interaction between agency membership and goal orientation, $\chi^{2}(2)=6.236, p=.04$, with a large effect size (Pallant, 2010), Cramer's V=.364. Odds ratios indicated that Ambulance participants were 11.58 and 9.90 times more likely to hold approach (attack) goals than Police and Fire participants, respectively. Fire participants were 1.18 times more likely to hold approach goals than Police participants.

Data were explored to see how participants prioritised their goals in order of importance (they were asked to list their top three goals in order). Police participants' were consistently split between approach and avoidance goals; Fire participants' goals became 
increasingly approach oriented; and Ambulance participants' consistently prioritised approach goals (Figure 4). These differences seem to be a function of agency-specific responsibilities. The Police are responsible for both responding to and positively impacting upon the unanticipated emergency (attack/approach) whilst also protecting the wider public and normality from adverse outcomes (defend/avoid); the Fire and Rescue Service seek to rescue civilians (attack/approach) but this involves inherent risk to their responders during rescues (defend/avoid); and the Ambulance Service held consistent attack/approach goals as their main purpose during emergencies is to treat patients. Yet, despite these inconsistencies, when participants ranked whether they believed goals across team members were inconsistent, their mean score rested between 'disagree' and 'somewhat disagree' $(M=2.31, S D=1.21)$, suggesting that they believed inter-agency goals were relatively consistent. Thus, although self-reported goals were agency-specific, commanders were not explicitly aware of these differences.

\section{Inter-agency team goal orientations and the timing of decision logging}

The total time that it took teams to complete the exercise ranged from 66 to 90 minutes, with a mean exercise length of 78.61 minutes. The time taken to log decisions was measured at two decision points: (i) identification of hot/warm/cold zones (inject 2); and (ii) the decision on whether to commit additional non-specialist staff to the risk area or not (inject 7) (Table 1). These two decisions were identified by SMEs as being especially challenging because they were non-time bounded choices that were ambiguous, high-stakes and required agreement from all three agencies. Decision logs were used to calculate the time taken to respond to each decision from time-zero (i.e. inject of information) to time-one (i.e. logged joint decision). SMEs helped to identify the point of time when a relevant decision had been logged.

An issue with the data was that goals were recorded at the individual level, but the dependent variable (i.e. time) was recorded at a collective (i.e. team) level. This meant it was not possible to run standard statistical tests (e.g. t-tests) to see whether goals (individual-level data) interacted with decision timing (team-level data). This is an acknowledged limitation and future research should mitigate these effects by recording explicit statements of collective goals during decision logging and/or testing for effects in individual decision making settings (see discussion). To deal with this limitation, data was coded to explore the team's collective goal orientation using a majority rule (e.g. if the majority of team members reported approach 
goals then the team was coded as being dominantly approach oriented) (Figure 5). It is recognised that this method of coding is not ideal as it is not possible to ascertain whether a team whose members mainly expressed approach goals were necessarily guided by this goal type throughout the exercise. However, as the results were intriguing and derived from a specialist sample of practitioners, we have reported them as a cautious platform to guide further research.

A Mann Whitney U-test was used as data from 'attack/approach' teams was nonnormally distributed (Pallant, 2010). Teams that mainly held attack/approach goals were significantly slower $(M d n=84.00)$ at completing the simulation than teams who held defend/avoid goals ( $M d n=71.00), U=150.00, z=-2.34, p=.019, r=-.34$. Interestingly, attack/approach teams were significantly faster at making decisions during the initial 'zoning' task ( $M d n=11.00)$ compared to avoid teams $(M d n=16.00), U=104.50, z=-3.36$, $p=.001, r=-.49$; however, defend/avoid teams were faster $(M d n=2.00)$ at decision making than approach teams $(M d n=9.50)$ during the 'non-specialist staff' task. In fact, the difference between these groups was so wide that the range of times for each group did not overlap, resulting in a U-value of .000. Avoid teams ranged between 2 and 3 minutes to log a joint choice compared to approach teams who ranged from 5 to 36 minutes. Thus, although this difference is significant, $U=.00, z=-5.70, p<.001, r=-.83$, it must be interpreted with caution. It seems that attack/approach goals facilitated faster decision making during the initial stages of the incident by focussing the team on maximising positive outcomes and taking action. However, later on in the incident, when competing task demands increased, defend/avoid goals facilitate faster action by focussing the team on taking action that had the 'least-worst' negative impact on the situation.

To try and explain this unusual finding, we looked at what decision the teams made for the non-specialist staff task. Attack/approach teams were relatively split in their decision as $\mathrm{n}=3$ committed and $\mathrm{n}=4$ did not commit; however, defend/avoid teams favoured the option to not commit non-specialist staff to the risk area ( $n=4$ did not commit; $n=1$ committed) (Figure 6). It seems that defend/avoid teams rapidly selected the option that was most closely anchored to their goal focus; they avoided negative consequences by quickly opting for the more defensive option by not risking emergency responder safety. Attack/approach teams however were fairly split with regards to whether they committed or not, possibly as their desire to make a positive impact on the situation (approach) was incompatible with the complexity and risk of the situation. Thus, attack/approach goals seem to be most useful 
when it is possible to optimise outcomes (e.g. take fast action to treat patients and save life); whereas defend/avoid goals are useful to aid fast decision making when the situation is complex with competing task demands (e.g. if accessing casualties is too high risk then prioritise emergency responder safety).

\section{Discussion}

This paper used a simulated terrorism exercise to explore whether the self-reported goals between emergency responders were consistent. It had two research questions, which are outlined in Table 4 with their answers and additional context-rich (i.e. relating to the emergency response domain) and context-general (i.e. relating to multi-team decision making) implications. It was found that, although participants perceived inter-agency goals to be consistent, their self-reported objectives differed. Self-reported objectives reflected agency-specific priorities. Police commanders held both attack/approach and defend/avoid goals, relating to their need to respond to the incident whilst protecting the wider community from further harm; Fire and Rescue commanders initially prioritised defend/avoid goals and then shifted towards attack/approach goals, relating to their need to take initial steps to mitigate risk to emergency responders in order to undertake complex procedures to rescue victims; and Ambulance commanders were consistently attack/approach oriented, relating to their primary role to treat casualties. Importantly however, commanders believed inter-team goals were consistent. This reflects a gap between an assumption of shared goals and the reality of self-reported objectives, which are agency-specific. These differences are especially prevalent when looking at how different agencies prioritise different goals at different phases of the incident. This has implications for 'joint' decision making, as it suggests that commanders are not consciously aware of the differences in their objectives at different phases of the incident. As such, this presents a risk of miscommunication, duplicated efforts and inconsistent behaviour at the multi-team level. As this paper was largely exploratory and so did not explicitly test decision quality, an avenue for further research is to identify whether goal inconsistency is associated to poor decision quality (Table 4).

At the multi-team level, it was found that attack/approach teams were slower at decision logging across the incident as a whole. They made faster decisions during the initial zoning task, but defend/avoid teams logged faster decisions for the 'non-specialist staff' task. This was an unexpected finding and contrary to traditional assumptions that 'approach' goals facilitate action (Elliot et al., 2006; 2013). This may be explained by the context of these two 
tasks. The early 'zoning' task was at the start of the exercise. This was when there was a lack of information about the incident, which meant that commanders had fewer competing task demands whilst awaiting further updates. As such, those who were motivated to take positive and attacking action (approach) made faster choices. Comparatively, the 'non-specialist staff' decision was much later in the incident, when teams also had to deal with the outbreak of a fire, the movement of shooters to the underground station and an increasing number of fatalities. It is possible that these multiple competing task-demands made the desire to take positive action unrealistic; the context was too challenging to achieve optimal outcomes. Instead, focussing on the avoidance of negative consequences by defending the situation lead to faster action. This was supported by analyses of how teams responded to this binary choice, where defend/avoid teams tended to chose not to commit responders; they rapidly took a defensive strategy as it matched their intrinsic motivation to avoid negative consequences. A context-rich further research question (Table 4) is to investigate whether an intervention to train commanders to consider 'least-worst' defensive (avoidant) goals when faced with multiple task commands could speed up decision making. Commanders are team leaders and so having the confidence to commit to some (defensive) action, whilst considering contingencies, might be more adaptive than redundantly deliberating and failing to make any decision at all. However, due to the limitations with decision time data in this study (goal orientation was recorded at the individual-level and time collected at the teamlevel), these conclusions are reported with caution (see limitations). Further context-general research to investigate how goal orientation interacts with task complexity and decision timing is needed (Table 4).

\section{Interoperability and joint decision making at emergency incidents}

JESIP has sought to increase the frequency and effectiveness of interoperability and joint working in the UK emergency services. Its decision model, the JDM, which is designed to guide multi-team decision making at critical and major incidents, has two central goals: to 'save life' and 'reduce harm' (JESIP, 2013). If these goals are perceived by responders to be clear and unambiguous, they should enhance interoperability by translating intra-agency objectives into collaborative action (Marks et al., 2001; Mathieu et al., 2000; Millward et al., 2010). However, results from this study suggested that, although participants thought they were working towards collective goals, their self-report goals were very different. It is possible that this may be due to the relatively abstract nature of JDM goals to 'save life' and 'reduce harm', creating ambiguity and inconsistent assumptions. Poorly defined goals are 
associated with poor team coordination (Hackman, 2002; Locke \& Latham, 1990) and reduce the likelihood of action and goal accomplishment (Marks et al., 2001; Alison et al., 2015). Commanders might share common goal intentions (i.e. to 'save life') yet disparate and contradictory implementation intentions for how they will achieve this goal (Gollwitzer \& Sheeran, 2006). Research has suggested that implicit, unconscious and emotional goals are distinct from explicit, cognitive and rational goals (Schultheiss \& Brunstein, 1999). Commanders might explicitly state the 'save life' goal, but implicitly orient towards intraagency objectives. The apparent disconnect between implicit self-reported goals and explicit statements of inter-agency goal cohesion could explain why commanders perceived goals to be aligned despite differences in their self-reported objectives.

The results of this study therefore raise questions about whether the strategic goals outlined in the JDM are useful for inter-agency coordination (albeit it is acknowledged that this study did not explore decision making quality). The goals to 'save life' and 'reduce harm' need greater clarity in order to be effective on the incident ground. The methods by which one might 'save life' or 'reduce harm' are numerous and specific to the situation and the skills of the individual or team. Does 'save life' refer to the lives of civilians in the risk area or the wider public? And for how long does 'save life' take precedent over the risk to lives of the emergency responders? There are no right or wrong answers to these questions and the interpretation of 'save life' goals can vary greatly. Results from this study suggest that commanders do not share common objectives and that these differences fluctuate in terms of how agencies prioritise their goals. Police commanders expressed goal conflict between attack/approach and defend/avoidance goals, Ambulance commanders held consistently high attack/approach goals, whereas the Fire and Rescue commanders shifted from initial defend/avoid goals to attack/approach goals. These differences arguably mirror differences in agency-specific roles and responsibilities. Police not only hold responsibility for taking action to positively impact upon the incident (e.g. neutralise threat), but they are also responsible for defending post-incident normality and the wider protection of the public; explaining their relative split between self-reported attack/approach and defend/avoid goals. The Ambulance Service's primary role at emergencies is to treat and transfer patients; explaining their consistent desire take attack/approach. For the Fire Service, their shift in goals from defend/avoid to attack/approach is reflective of their core aim to rescue casualties (approach), but, practically, this often requires a great deal of technical skill and risk to responders; explaining their initial defensive goal to establish safe working practices to 
'protect emergency responders'. All three agencies might share the superordinate goal to 'save life', yet their behavioural objectives relating to whose life and how they intend to do this are very different. It is recommended that a greater focus how different agencies prioritise these different goal types, rather than a focus on vague strategic goals, could enable greater multi-team coordination and interoperability.

\section{The usefulness of defensive/avoid goals in complex decision domains}

Research has generally suggested that approach goals are useful for decision making and action. They are associated with positive affect and movement towards positive stimuli (Bossuyt et al., 2014; Elliot, 2006). Avoid goals, however, are maladaptive and associated with the desire to avoid performing poorly, negative affect, anxiety and poor self-regulation of behaviour (Oertig, Schuler, Brandstatter, Rosekes \& Elliot, 2013; Elliot, 2006). Data in this study was coded to reflect these goals, whereby goals linked to 'attacking' the incident were coded as approach and goals linked to 'defending' the incident coded as avoid. Preliminary findings from this study were inconsistent with the traditional literature on approach-avoid goals. As expected, approach motivations were associated to faster decision making in the early 'zoning' task; they seemed to galvanise teams into taking action by logging rapid decisions. However, unexpectedly, it was found that teams using defend/avoid goals made faster decisions during the later 'non-specialist staff' decision. The question is, does this imply that attack/approach goals are not useful in certain contexts, or that defend/avoid goals might actually facilitate faster decision making in these contexts?

One explanation for this unusual finding relates to the compatibility of approach goals to complex task environments. The initial 'zoning' task had few competing task demands as it was presented during the very early stages the incident (inject two), where decision processing was dominated by situational assessment rather than juggling multiple task demands. Alternatively, the 'non-specialist staff' task was presented much later into the incident (inject seven), when multiple other tasks competed for attention (i.e. additional fire, moving shooters, more fatalities). Attack/approach goals might have galvanised action earlier on in the incident, when there were fewer competing tasks to respond to; whereas defend/avoid goals increased decision speed during the 'non-specialist' staff choice as commanders rapidly selected the option that would avoid causing negative consequences (i.e. not commit additional responders). When the task environment is complex and high risk, the desire to take defensive action to limit risk and avoid negative consequences is intrinsically 
compatible; inducing a faster response. Indeed, research on exam performance in schools has indicated how approach goals are positively related to exam performance, but that their positive impact on performance is mediated by perceived difficultly of the exam (Darnon, Butera, Mugny \& Hulleman, 2009). Approach goals facilitate performance, but only when the task is perceived to be easy or obtainable (Hackman, 2002; Locke \& Latham, 1990). Therefore, when incident complexity increases, approach goals might no longer improve performance or decision speed. It is suggested that a greater consideration of the characteristics of the decision environment should be incorporated when setting task objectives, to ensure that goals are compatible with the decision context.

\section{Limitations}

Before discussing the implications for this research, it is important to identify and respond to an acknowledged limitation to the design of this study relating to decision time data. Whereas data for decision timing was coded at the collective team level; self-reported goals were collected at the individual level. Although this is reflective of real-world multiteam contexts, wherein team members might hold many different goals, it meant that it was difficult to ascertain how goals interacted with the time it took for the team to make a choice. Yet, as emergency responding has been historically criticised for delayed choice rather than making poor choices (Patrick, 2011; Pitt, 2008), time was considered to be a variable of interest. The research team decided to code each group as being 'attack/approach' or 'defend/avoid' oriented by using a majority rule: if the majority of individuals within a team held approach goals then the team was coded as being approach oriented and vice versa for defend/avoid. This made it possible to explore how the dominant goal of a team interacted with the time it took them to log their joint choices.

We acknowledge that this solution is not ideal. The decision on whether to include analyses on decision time in the manuscript was debated by the authors; findings were theoretically interesting, yet had the potential for Type 1 error. Indeed, if the sample was derived from non-expert practitioners, then further data collection to provide support to these conclusions would be possible. However, as data was from a unique sample of hard-toaccess, expert emergency commanders, this was not possible. Furthermore, exposing the general population to this highly complex simulation, which was purposefully designed for emergency commanders, would be unfeasible as they would lack the knowledge required to make decisions. With this in mind, it was decided these findings would be included, 
providing that these limitations were made clear to the reader and treated with caution. The authors felt that their inclusion was warranted in order to provide a spring board for further research, outlined in Table 4. Future research on the relationship between goal orientation, task complexity and decision timing in the general population are encouraged.

\section{Implications}

There are two core findings to this research (Table 4). In response to RQ1, it was found that, despite the assumption that goals were consistent between agencies, goals were in fact very different and role-specific. In response to RQ2, attack/approach goals facilitated faster team action during the initial stages of the incident, but when the incident became more complex with competing task demands, defend/avoid teams logged faster choices. Both the context-rich (i.e. related to emergency responding) and context general (i.e. general decision making) implications for these findings will be discussed.

\section{Defining distinct 'save life' goals to facilitate collaborative, rather than collective,} decision making. A context-rich implication for the findings of RQ1 relate to recommendations for enhancing goal clarity in emergency settings. A study to qualitatively explore the 'save life' mantra by comparing how different agencies conceptualise this goal in different emergency response scenarios would be useful. This could be used to develop further training in order to educate different authorities about the nuanced differences in their role-specific objectives and associated pressures. Training to enhance goal imagery (i.e. the mental representation of pursuit and attainment of a goal) can facilitate implicit and explicit goal alignment (Schultheiss \& Brunstein, 1999). Using visual tools, for example, listing each agency's current top three objectives on an interactive tablet during incident response, could help commanders to contextualise each other's goals, identify how they can facilitate one another, and work more cohesively.

Secondly, despite the intention of the JDM to encourage more interoperable and 'joint' decision making (JESIP, 2013), it might be more useful to use a model that creates a greater awareness of differing agency objectives and upholds individual agency expertise. The idea that 'interoperability' should be judged according to how 'joint' agencies' decision making is, is arguably inconsistent with the complex task demands of the emergency incident environment (House, Power \& Alison, 2014). Emergencies require distributed expertise in the domains of policing, rescuing and treating casualties. Thus, in contrast to the JESIP concept of 'joint' and collective decision making, we argue for collaborative decision 
making, which enshrines the nuanced differences between agencies and draws strength from the wealth of expertise that can be derived from inter-agency coordination. A decentralised approach to decision making, where the Police. Fire, and Ambulance Services have clearly delineated roles and responsibilities and share explicit statements of tactical objectives, which are iteratively updated throughout the incident, might be more appropriate. A poor understanding of one's own and others' roles is a major cause of uncertainty in emergency response settings (Alison, Power, van den Heuvel \& Waring, 2015). Greater interoperability in the emergency services is important, but it must be taught in a manner that respects and enshrines the nuanced differences between agency-specific expertise.

\section{Investigating how goal focus interacts within complex, dynamic and ambiguous}

contexts. A context-general implication for the findings to RQ2 relates to assumptions about the use of approach and avoid goals; namely that approach goals are adaptive and avoidance goals are maladaptive. Although there were limitations with the current data set (as outlined above), results suggested that 'attack/approach' teams made fast decisions during the initial stages of the incident, but that 'defend/avoid' teams made faster choices later in the incident when tasks were more complex. Tying with earlier discussions, results could be interpreted to suggest that defend/avoid goals are adaptive in complex settings; focussing on more risk averse and defensive strategies could increase decision speed when faced with complexity. This is because individuals focus on action that could lead to the 'least-worst' outcomes as opposed to 'optimising' outcomes.

This presents an interesting avenue for research with regards to the compatibility of goals in different decision contexts. Arguably, when choices become overly complex, approach goals no longer facilitate fast action as individuals struggle to trade-off multiple competing sub-goals and tasks; whereas avoid goals facilitate choice by shifting focus towards 'leastworst' outcomes. A limitation with the present study was that approach/avoid goals were coded at the end of the simulation and thus it is not possible to explicitly identify participants' specific goals at the point of decision making. Furthermore, there were no explicit measures of perceived decision complexity during the simulation. This is mainly a product of the fact that this was an emergent finding and so was not anticipated in the initial design of the study. It would be useful to extend this investigation in context-general settings by exploring how goal orientation, perceived complexity and decision timeliness interact with more general decision making. This would help to develop a psychological understanding of the functional relevance of approach goals when operating in novel and complex environments. In terms of 
context-rich implications, practitioner training that encourages responders to utilise 'avoid' or 'defend' goals when dealing with competing task demands could enable more decisive behaviour.

\section{Conclusion}

This paper explored command-level goal setting during a simulated terrorist incident. Although commanders perceived their goals to be similar, their self-reported goals were very different: Police commanders were torn between approach and avoid goals; Fire commanders prioritised initial avoidance, before shifting to approach goals; and Ambulance commanders were consistently approach oriented. This seemed to reflect agency-specific roles and responsibilities: the Police Service have responsibilities for both the responding to the incident (attack/approach) whilst preventing harm arising in the wider community (defend/avoid); the Fire Service often take high-risk procedures and use complex apparatus that risk emergency responder safety (defend/avoid), but then, once they have established safety precautions, prioritise the rescuing of civilians (attack/approach); and the predominant role for the Ambulance Service is to provide treatment to patients (attack/approach). However, participants erroneously perceived their goals to be consistent. This suggests that abstract 'save life' goals and a focus on purely 'joint' decision making might contribute to a poor understanding of the nuanced differences between agency-specific objectives during emergency responding. Thus, it is suggested that a distributed decision model that encourages collaborative, rather than collective or joint, choices might have a greater benefit during multi-team responding. At the inter-team level, attack/approach goals led to faster decision making early on in the incident, whereas defend/avoid goals led to faster action later in the incident. It is suggested that attack/approach goals are useful when there are few competing task demands, whereas defend/avoid goals facilitate action when the situation is complex by focusing individuals on achieving 'least-worst' as opposed to 'optimal' outcomes. Future research could test the usefulness of different goal types when operating in complex task environments. It is also suggested that commander training in the emergency services place a greater focus on the distinction between 'attack' and 'defend' goals to anticipate when 'leastworst' defensive goals might be more appropriate. 


\section{References:}

Alison, L., \& Crego, J. (2007). Policing critical incidents: Leadership and critical incident management. Devon, England: Willan Publishing.

Alison, L., Power, N., van den Heuvel, C., \& Waring, S. (2015). A taxonomy of endogenous and exogenous uncertainty in high-risk, high-impact contexts. Journal of Applied Psychology, 100, 1309-1318.

Alison, L., Power, N., van den Heuvel, C., Humann, M., Palasinksi, M., \& Crego, J. (2015). Decision inertia: deciding between least worst outcomes in emergency responses to disasters. Journal of Occupational and Organisational Psychology, 88(2), 295-321.

Alison, L., van den Heuvel, C. Waring, S., Power, N., Long, A., O’Hara, T., \& Crego, J. (2013). Immersive simulated learning environments for researching critical incidents: A knowledge synthesis of the literature and experiences of studying high-stakes strategic decision making. Journal of Cognitive Engineering and Decision Making, 7(3), 255-272.

Bharosa, N., Lee, J., \& Janssen, M. (2010). Challenges and obstacles in sharing and coordinating information during multi-agency disaster response: Propositions from field exercises. Information Systems Frontier, 12, 49-65.

Bossuyt, E., Moors, A., \& De Houwer, J. (2014). On angry approach and fearful avoidance: The goal-dependent nature of emotional approach and avoidance tendencies. Journal of Experimental Social Psychology, 50, 119-124.

Brown, B., Crawford, P., \& Darongkamas, J. (2000). Blurred roles and permeable boundaries: the experience of multidisciplinary working in community mental health. Health \& Social Care in the Community, 8(6), 425-435.

Carver, C.S., \& White, T.L. (1994). Behavioral inhibition, behavioural activation, and affective responses to impending reward and punishment: The BIS/BAS Scales. Journal of Personality and Social Psychology, 67(2), 319-333.

Chen, R., Sharman, R., Rao, H.R., \& Upadhyaya, S.J. (2008). Coordination in emergency response management: Developing a framework to analze coordination patterns 
occurring in the emergency response life cycle. Communications of the ACM, 51(5), 66-73.

Corr, P.J., DeYoung, C.G., \& McNaughton, N. (2013). Motivation and personality: A Neuropsychological perspective. Social and Personality Psychology Compass, 7/3, 158-175.

Darnon, C., Butera, F., Mugny, G., \& Hulleman, C.S. (2009). “Too complex for me!” Why do performance-approach and performance-avoidance goals predict exam performance? European Journal of Psychology of Education, 24(4), 423-434.

Drach-Zahavy, A., \& Erez, M. (1997). Difficult goals: a challenge or a threat? The effects of goals, stress and hope on the performance of complex tasks. Paper presented at the Academy of Management Convention, Boston, MA.

Drach-Zahavy, A., \& Somech, A. (1999). Constructive thinking: a complex coping variable that distinctively influences the effectiveness of specific difficult goals. Personality and Individual differences, 27, 969-984.

Edmondson, A. (1999). Psychological safety and learning in behaviour in work teams. Administrative Science Quarterly, 44, 350-383.

Elliot, A.J. (2006). The hierarchical model of approach-avoidance motivation. Motivations and Emotion, 30, 111-116.

Elliot, A.D., Eder, A.B., \& Harmon-Jones, E. (2013). Approach-avoidance motivation and emotion: convergence and divergence. Emotion Review, 5(3), 308-311.

Gollwitzer, P.M. (1993). Goal achievement: The role of intentions (pp.141-185). In W. Stroebe \& M. Hewstone (eds). European review of social psychology. Chichester, England: Wiley.

Gollwitzer, P.M. (1999). Implementation intentions: Strong effects of simple plans. American Psychologist, 54(7), 493-503.

Gollwitzer, P.M., \& Sheeran, P. (2006). Implementation intentions and goal achievement: A meta-analysis of effects and processes. Advances in Experimental Social Psychology, 38, 69-119. 
Gore, J., Banks, J., Millward, L., \& Kyriakidou, O. (2006). Naturalistic decision making and organizations: Reviewing pragmatic science. Organization Studies, 27(7), 925-942.

Gray, J.A., \& McNaughton, N. (2000). The Neuropsychology of Anxiety: An Enquiry into the Functions of the Septo-Hippocampal System. Oxford, England: Oxford University Press.

Hackman, J.R. (2002). Leading Teams: Setting the stage for great performances. Boston, Massachusetts; Harvard Business School Press.

He, H., Baruch, Y., \& Lin, C.P. (2014). Modelling team knowledge sharing and team flexibility: The role of within-team competition. Human Relations, 67(8), 947-978.

House, A., Power, N., \& Alison, L. (2014). A systematic review of the potential hurdles of interoperability to the emergency services in major incidents: recommendations for solutions and alternatives. Cognition, Technology \& Work, 16, 319-335.

Hutchins, S.G., \& Kendall, T. (2011). The role of cognition in team collaboration during complex problem solving (pp. 69-89). In K.L. Mosier \& U.M Fischer (eds). Informed By Knowledge. Hove: Psychology Press.

Hydra Foundation (2015). Our Projects. Accessed on $25^{\text {th }}$ May 2015, available from http://www.hydrafoundation.org/our-projects

JESIP (2013). Joint Doctrine: The Interoperability Framework. London: JESIP.

Locke, E.A., \& Latham,, G.P. (1990). A Theory of Goal Setting and Task Performance. Englewood Cliffs, NJ: Prentice-Hall.

Locke, E.A., \& Latham, G.P. (2002). Building a practically useful theory of goal setting and task motivation: A 35 year odyssey. American Psychologist, 57, 705-717.

Locke, E.A., \& Latham, G.P. (2006). New direction in goal-setting theory. Current Directions in Psychological Science, 15(5), 265-268.

Marks, M.A., Mathieu, J.E., \& Zaccaro, S.J. (2001). A temporally based framework and taxonomy of team processes. Academy of Management Review, 26(3), 356-376.

Mathieu, J.E., Heffner, T.S., Goodwin, G.F., Salas, E., \& Cannon-Bowers, J.A. (2000). The influence of shared mental models on team process and performance. Journal of Applied Psychology, 85(2), 273-283. 
McAndrew, C., \& Gore, J. (2012). Understanding preferences in experience-based choice: A study of cognition in the "wild". Journal of Cognitive Engineering and Decision Making, 7(2) 179-197.

Militello, L.G., Sushreba, C.E., Branlat, M., Bean, R., \& Finomore, V. (2015). Designing for military pararescue: Naturalistic decision-making perspective, methods, and frameworks. Journal of Occupational and Organizational Psychology, 88(2), 251272.

Millward, L.J., Banks, A., \& Riga, K. (2010). Effective self-regulating teams: a generative psychological approach. Team Performance Management: An International Journal. 16(1/2), 50-73.

Oertig, D., Schuler, J., Schnelle, J., Brandstatter, V., Roskes, M., \& Elliot, A.J. (2013). Avoidance goal pursuit depletes self-regulatory resources. Journal of Personality, 81(4), 365-375.

Orasanu, J. (1993). Shared problem models and flight crew performance (pp. 255-285). In N. Johnston, N. McDonald \& R.Fuller (eds). Aviation psychology in practice. Aldershot, England: Ashgate.

Orasanu, J., \& Lieberman, P. (2011). NDM issues in extreme environments (pp.3-22). In K.L. Mosier \& U.M Fischer (eds). Informed By Knowledge. Hove: Psychology Press.

Pallant, J. (2010). SPSS Survival Manual: A step by step guide to data analysis using SPSS. Berkshire, England: Open University Press.

Paton, D., \& Flin, R. (1999). Disaster stress: an emergency management perspective. Disaster Prevention and Management: An International Journal, 8(4), 261-267.

Patrick, J. (2011). Evaluation Insights Haiti Earthquake Response Emerging Evaluation Lessons. Evaluation Insights, 1, 1-13.

Pitt, M. (2008). Flood Review: Learning lessons from the 2007 floods. Retrieved from: http://webarchive.nationalarchives.gov.uk/20100807034701/http:/archive.cabinetoffic e.gov.uk/pittreview/_/media/assets/www.cabinetoffice.gov.uk/flooding_review/pitt_re view_full\%20pdf.pdf 
Schultheiss, O.C., \& Brunstein, J.C. (1999). Goal imagery: Bridging the gap between implicit motives and explicit goals. Journal of Personality, 67, 1-38.

Seijts, G.H., \& Latham, G.P. (2000). The effects of goal setting and group size on performance in a social dilemma. Canadian Journal of Behavioral Science, 32, 104116.

van den Heuvel, C., Alison, L., \& Power, N. (2014). Coping with uncertainty: police strategies for resilient decision-making and action implementation. Cognition, Technology \& Work. 16, 25-45.

Waring, S.K., Alison, L.J., Cunningham, S., \& Whitfield, K.C. (2013). The impact of accountability on motivational goals and the quality of advice provided in crisis negotiations. Psychology, Public Policy and Law, 19(2), 137-150.

Yates, J.F. (2003). Decision Management. San Francisco: Jossey-Bass.

Yearta, S.K., Maitlis, S., \& Briner, R.B. (1995). An exploratory study of goal settings in theory and practice: A motivational technique that works? Journal of Occupational and Organizational Psychology, 68, 237-252. 


\section{Tables:}

Table 1: Simulation timeline

\begin{tabular}{|c|c|c|c|}
\hline Inject & Title & $\begin{array}{l}\text { Message } \\
\text { source }\end{array}$ & Details \\
\hline 1 & $\begin{array}{l}\text { Initial callout } \\
\text { message }\end{array}$ & $\begin{array}{l}\text { Control centre } \\
\text { - Phone call } \\
\text { (AUDIO) }\end{array}$ & $\begin{array}{l}\text { Multiple } 999 \text { calls being received. Reports } \\
\text { of } 3 \text { men on Station platform who have } \\
\text { opened fire with automatic weapons at } \\
\text { civilians on platform. Rush hour trains. }\end{array}$ \\
\hline 2 & Zoning task & $\begin{array}{l}\text { Communicator } \\
\text { (TEXTUAL) }\end{array}$ & $\begin{array}{l}\text { Delegates told they are now at the RVP. } \\
\text { They have been provided with maps and } \\
\text { must decide upon hot/warm/cold zones and } \\
\text { place their FCP. }\end{array}$ \\
\hline 3 & $\begin{array}{l}\text { Civilian } \\
\text { message }\end{array}$ & $\begin{array}{l}\text { Civilian - live } \\
\text { message } \\
\text { (AUDIO) }\end{array}$ & $\begin{array}{l}\text { Frantic message from a civilian who was } \\
\text { inside the station. Informs of a large } \\
\text { number of casualties bleeding out and that } \\
\text { shooters are still firing at civilians. }\end{array}$ \\
\hline 4 & $\begin{array}{l}\text { Casualty } \\
\text { update }\end{array}$ & $\begin{array}{l}\text { Control centre } \\
\text { - Phone call } \\
\text { (AUDIO) }\end{array}$ & $\begin{array}{l}\text { Multiple } 999 \text { calls being received. Same as } \\
\text { civilian information - people bleeding and } \\
\text { dying and gunmen still firing. }\end{array}$ \\
\hline 5 & $\begin{array}{l}\text { Shooters to } \\
\text { underground }\end{array}$ & $\begin{array}{l}\text { Control centre } \\
\text { - Phone call } \\
\text { (AUDIO) }\end{array}$ & $\begin{array}{l}\text { Report from Firearms Officers that } \\
\text { shooters have moved down into the } \\
\text { underground local lines of the train station. }\end{array}$ \\
\hline 6 & $\begin{array}{l}\text { Fire inside } \\
\text { station }\end{array}$ & $\begin{array}{l}\text { Control centre } \\
\text { - Phone } \\
\text { call(AUDIO) }\end{array}$ & $\begin{array}{l}\text { Reports that a fire has started in a bar } \\
\text { inside the train station with persons } \\
\text { trapped. Fire resources are stretched. }\end{array}$ \\
\hline 7 & $\begin{array}{l}\text { Non- } \\
\text { specialist } \\
\text { staff at RVP }\end{array}$ & $\begin{array}{l}\text { Firefighter - } \\
\text { Radio message } \\
\text { (AUDIO) }\end{array}$ & $\begin{array}{l}\text { Addition staff from FRS and AS arrived at } \\
\text { RVP. They are not trained to work in } \\
\text { firearms incident but are volunteering to } \\
\text { commit. Delegates must decide whether to } \\
\text { use them or not. }\end{array}$ \\
\hline $8 a$ & $\begin{array}{l}\text { Angry chief - } \\
\text { Commit }\end{array}$ & $\begin{array}{l}\text { FRS Chief - } \\
\text { Phone call } \\
\text { (AUDIO) }\end{array}$ & $\begin{array}{l}\text { If decide to commit - FRS Chief rings } \\
\text { demanding to know why non-specialist } \\
\text { staff have been committed into the risk } \\
\text { area. }\end{array}$ \\
\hline $8 b$ & $\begin{array}{l}\text { Angry chief - } \\
\text { Not } \\
\text { committed }\end{array}$ & $\begin{array}{l}\text { FRS Chief - } \\
\text { Phone call } \\
\text { (AUDIO) }\end{array}$ & $\begin{array}{l}\text { If decide to not commit - FRS Chief rings } \\
\text { demanding to know why non-specialist } \\
\text { staff have been committed to the risk area. }\end{array}$ \\
\hline 9 & TCG update & $\begin{array}{l}\text { Police officer - } \\
\text { Phone call } \\
\text { (AUDIO) }\end{array}$ & $\begin{array}{l}\text { A situational update message must be sent } \\
\text { to the strategic multi-agency team }\end{array}$ \\
\hline
\end{tabular}

Note: RVP = Rendezvous Point; FCP = Forward Command Point; TCG=Tactical

Coordinating Group 
Running Head: Approach and avoid goals in emergencies

Table 2: Example quotes to indicate how different goals were coded into the six goal types

\begin{tabular}{|c|c|}
\hline Goal Code & Example from questionnaire \\
\hline Save life/treat patients & $\begin{array}{l}\text { "save life", "patients first”, "save as much saveable life } \\
\text { as possible" }\end{array}$ \\
\hline $\begin{array}{l}\text { Protect emergency responders from } \\
\text { harm }\end{array}$ & $\begin{array}{l}\text { "safety of staff”, "protect crew safety”, "FRS H\&S and } \\
\text { welfare" }\end{array}$ \\
\hline $\begin{array}{l}\text { Establish shared situational } \\
\text { awareness/joint working }\end{array}$ & $\begin{array}{l}\text { "establish shared situational awareness of incident”, } \\
\text { "joint decision making”, "establish the LOE” }\end{array}$ \\
\hline Protect the public from further harm & $\begin{array}{l}\text { "minimise risk to members of public", "protect life of } \\
\text { civilians", "safety of public" }\end{array}$ \\
\hline Locate/neutralise threat & $\begin{array}{l}\text { "neutralise threat", "locate, contain and neutralise } \\
\text { threat", "to contain and locate the threat" }\end{array}$ \\
\hline Prepare for post-incident demands & $\begin{array}{l}\text { "return to normality”, "save property/prepare } \\
\text { evidence”, "preserve evidence for investigation" }\end{array}$ \\
\hline
\end{tabular}


Running Head: Approach and avoid goals in emergencies

Table 3: The ‘approach’ or 'avoidance' classification of each of the six goals

\begin{tabular}{ll}
\hline Goal orientation & Original goal \\
\hline Attack/approach goal & Save life/treat patients \\
& Establish shared situational awareness/joint working \\
& Locate/neutralise threat \\
Pefend/avoid goal & Protect emergency responders from harm \\
& Protect the public from further harm \\
& Prepare for post-incident demands \\
\hline
\end{tabular}


Table 4: Research questions and answers

\begin{tabular}{|c|c|c|c|}
\hline \multirow{2}{*}{$\begin{array}{l}\text { Research } \\
\text { question }\end{array}$} & \multirow[t]{2}{*}{ Findings } & \multicolumn{2}{|c|}{ Further research questions } \\
\hline & & $\begin{array}{c}\text { Context-rich (i.e. emergency } \\
\text { services related) }\end{array}$ & $\begin{array}{c}\text { Context-general (i.e. } \\
\text { multi-team decision } \\
\text { making) }\end{array}$ \\
\hline $\begin{array}{l}\text { RQ1: Are the } \\
\text { goals of the } \\
\text { Police, Fire and } \\
\text { Rescue and } \\
\text { Ambulance } \\
\text { Services } \\
\text { aligned when } \\
\text { responding to a } \\
\text { simulated } \\
\text { terrorist } \\
\text { incident? }\end{array}$ & $\begin{array}{l}\text { No. Although participants } \\
\text { perceived inter-agency goals } \\
\text { to be consistent, their self- } \\
\text { reported goals differed as a } \\
\text { result of their agency- } \\
\text { specific roles. Police } \\
\text { commanders held both } \\
\text { approach and avoidance; } \\
\text { Fire commanders initially } \\
\text { prioritised avoidance goals } \\
\text { and then shifted towards } \\
\text { approach goals; and } \\
\text { Ambulance commanders } \\
\text { were consistently approach } \\
\text { oriented. }\end{array}$ & $\begin{array}{l}\text { What does the goal to ‘save } \\
\text { life' mean to different } \\
\text { emergency services in terms } \\
\text { of tactical priorities when } \\
\text { responding to different types } \\
\text { of multi-agency incident? } \\
\text { Does a decision making } \\
\text { model that explicitly } \\
\text { identifies agency-specific } \\
\text { tactical goals lead to more } \\
\text { effective decision making } \\
\text { (i.e. better quality, faster } \\
\text { action) than the JDM, which } \\
\text { focusses on abstract, joint } \\
\text { ('save life') goals? }\end{array}$ & $\begin{array}{l}\text { Does goal } \\
\text { inconsistency when } \\
\text { operating in multi-- } \\
\text { team environments } \\
\text { lead to poor quality } \\
\text { decisions (e.g. bad } \\
\text { decisions; duplicated } \\
\text { efforts, contradictory } \\
\text { actions)? }\end{array}$ \\
\hline $\begin{array}{l}\text { RQ2: How } \\
\text { does goal } \\
\text { orientation } \\
\text { interact with } \\
\text { the time it takes } \\
\text { to make a } \\
\text { decision? }\end{array}$ & $\begin{array}{l}\text { Attack/approach goals led to } \\
\text { faster decision making } \\
\text { earlier on in the incident; } \\
\text { defend/avoid goals led to } \\
\text { faster decision making later } \\
\text { in the incident. Arguably } \\
\text { focussing on the } \\
\text { achievement defensive 'least } \\
\text { worst' outcomes was more } \\
\text { useful for decision } \\
\text { implementation when coping } \\
\text { with competing task } \\
\text { demands. }\end{array}$ & $\begin{array}{l}\text { - Would decision making } \\
\text { training that illuminates the } \\
\text { distinction between } \\
\text { 'attack/approach' and } \\
\text { 'defend/avoid' goals help } \\
\text { commanders to understand } \\
\text { the contexts wherein different } \\
\text { goal focusses are most } \\
\text { useful? }\end{array}$ & $\begin{array}{l}\text { - How do the use of } \\
\text { attack/approach and } \\
\text { defend/avoid goals } \\
\text { interact with task } \\
\text { complexity, decision } \\
\text { timeliness and } \\
\text { decision quality? }\end{array}$ \\
\hline
\end{tabular}




\section{Figures:}

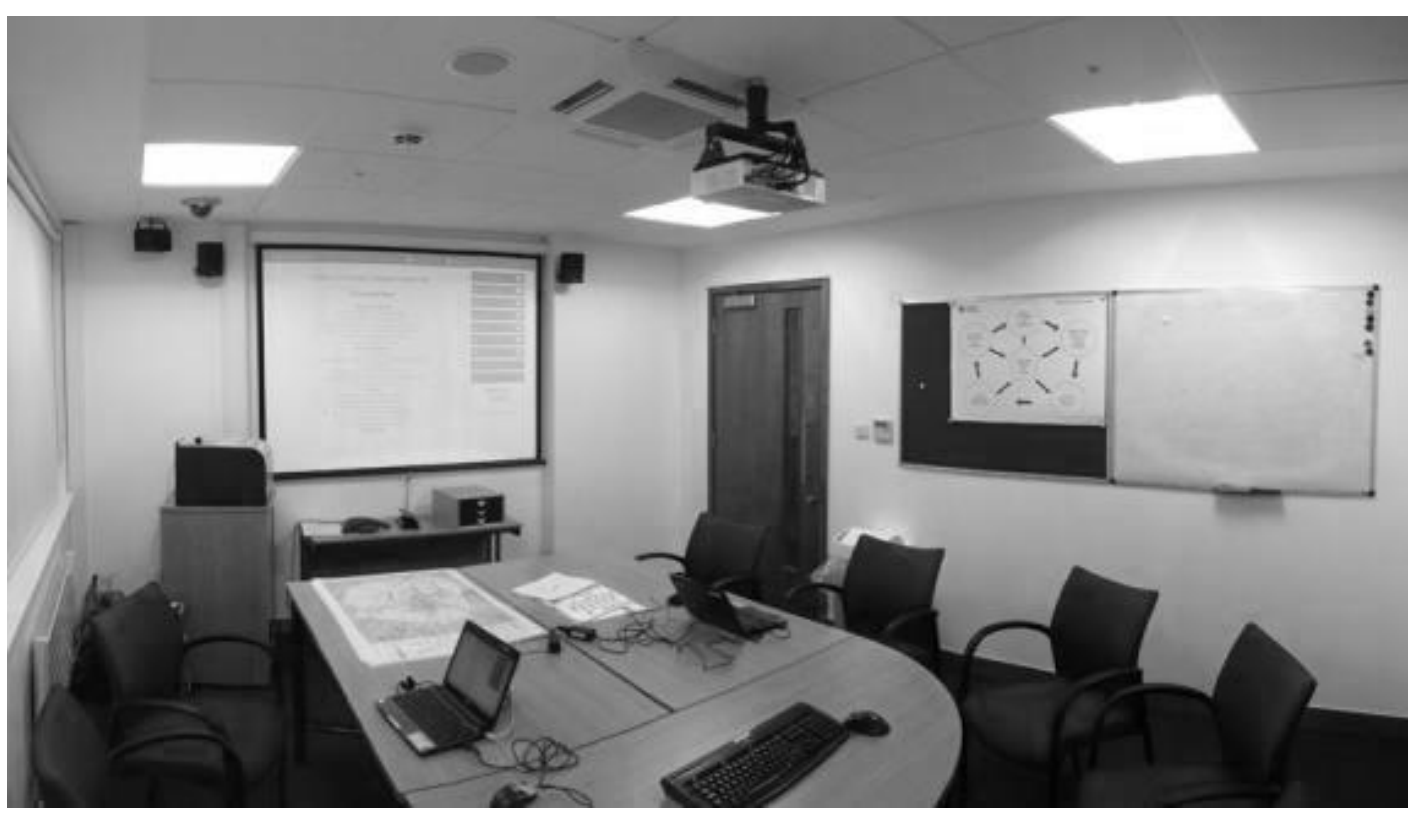

Figure 1: A typical Hydra 'syndicate room’ 
Running Head: Approach and avoid goals in emergencies

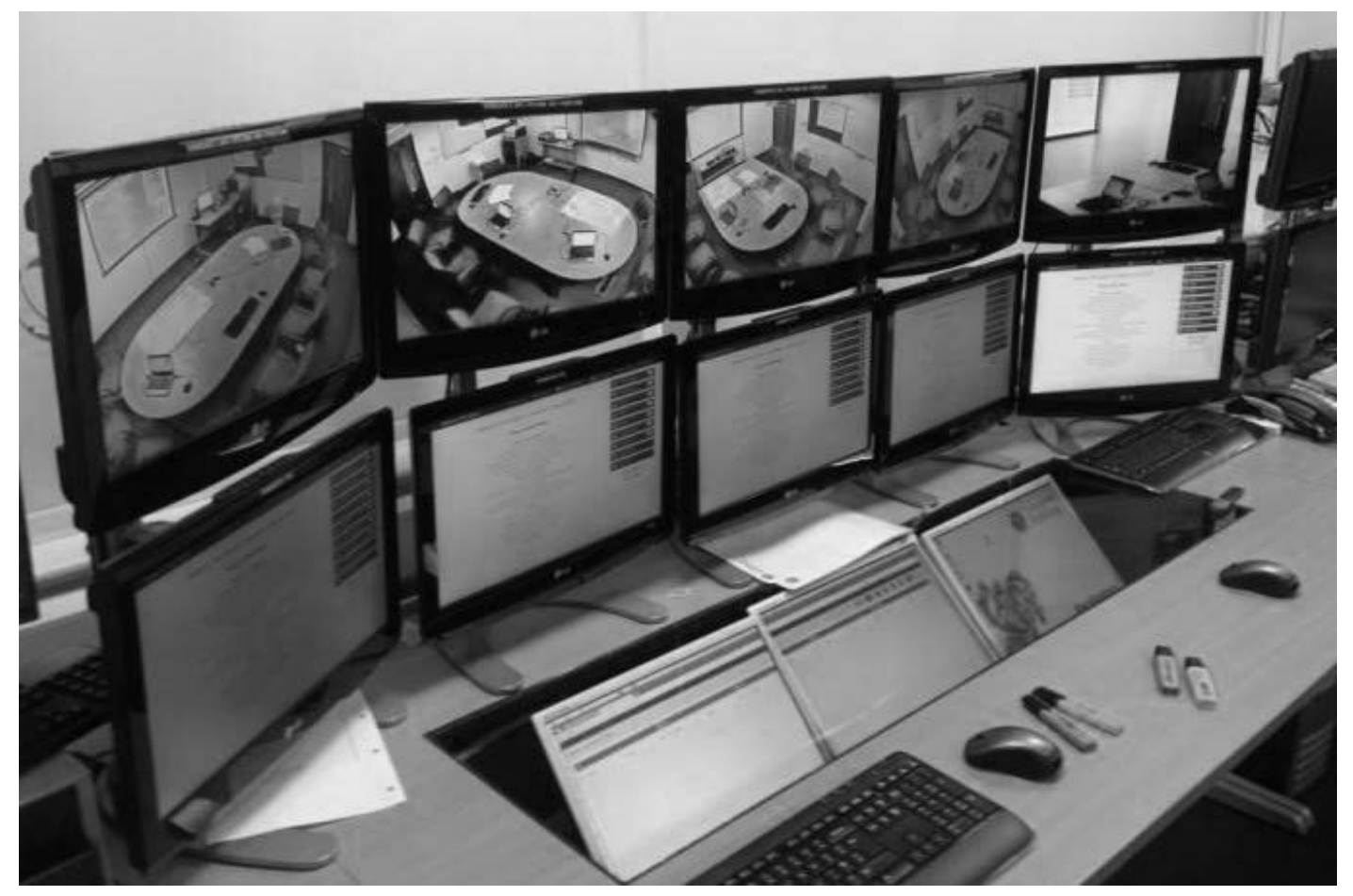

Figure 2: A typical Hydra 'control room' 


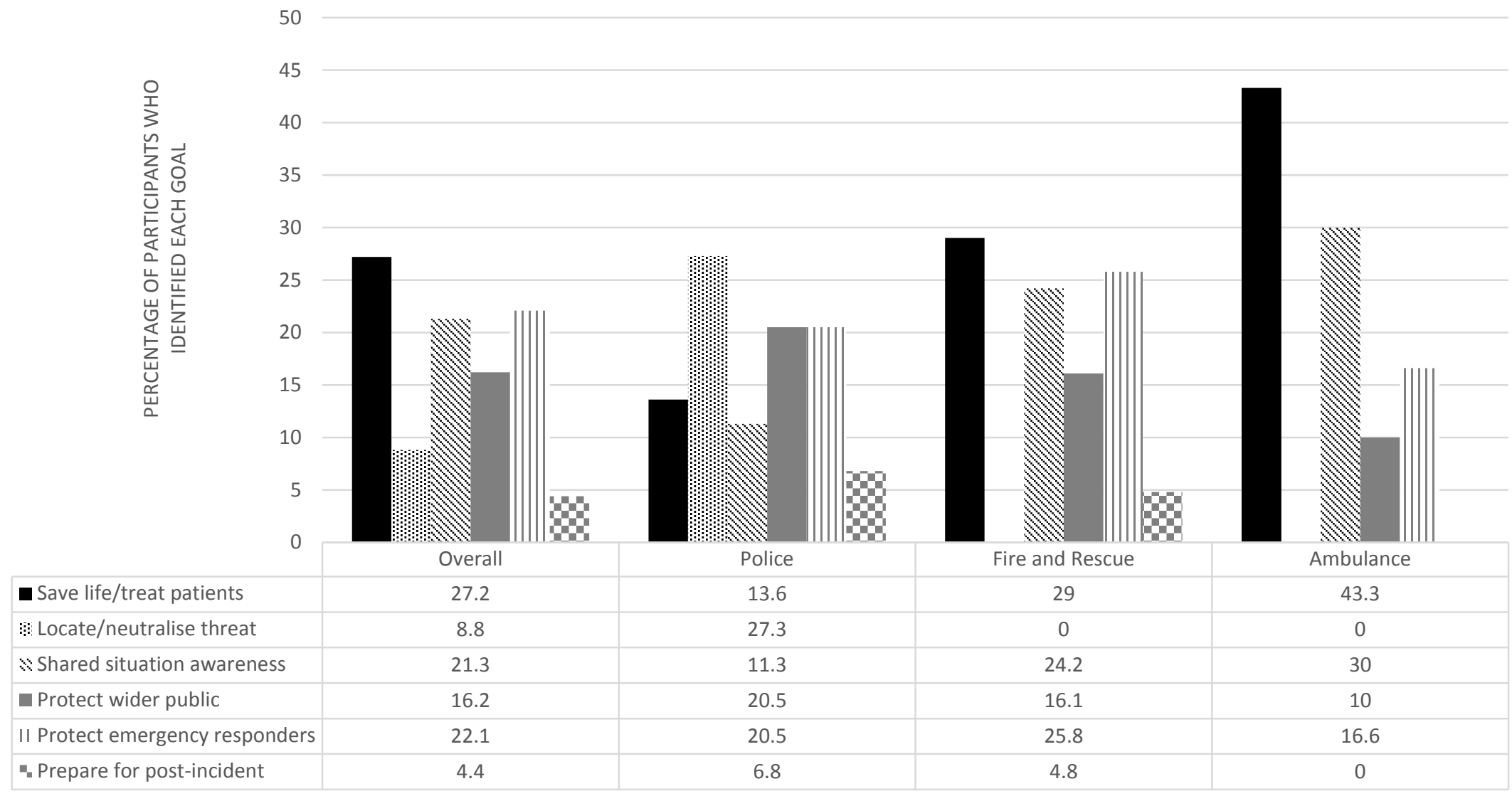

Figure 3: A figure to represent how participants in different agencies identified different types of goals 


\section{PERCENTAGE OF 'APPROACH' GOALS}

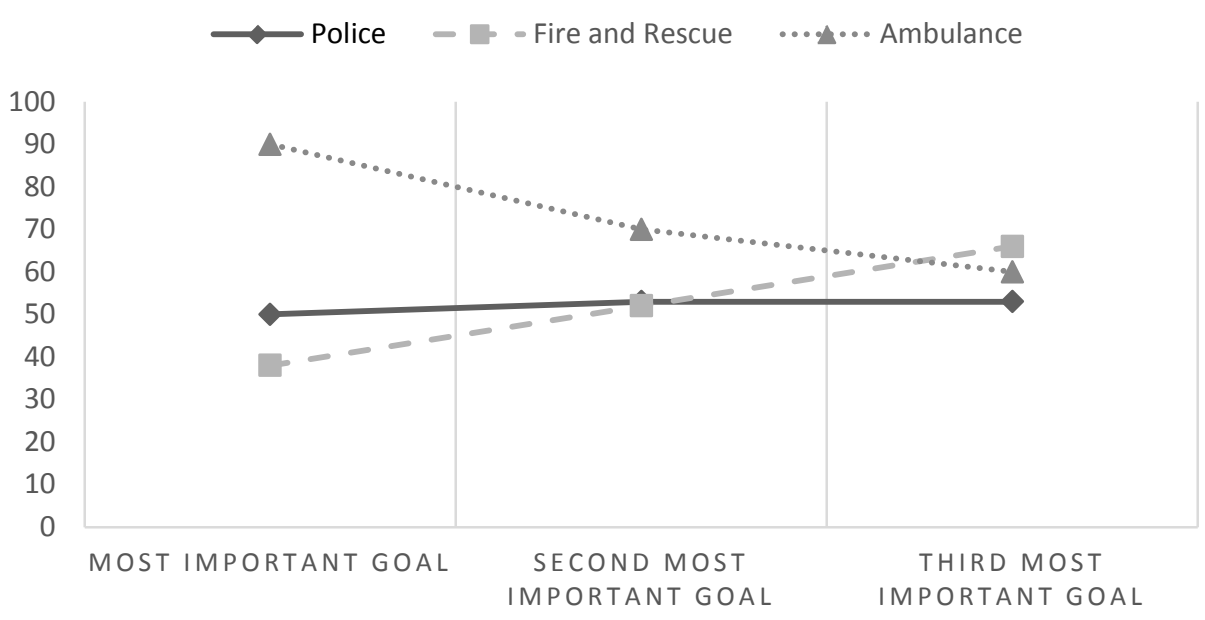

Figure 4: Percentage of participants within each agency who identified 'attack/approach' goals as their most important, second most important and third most important goals 


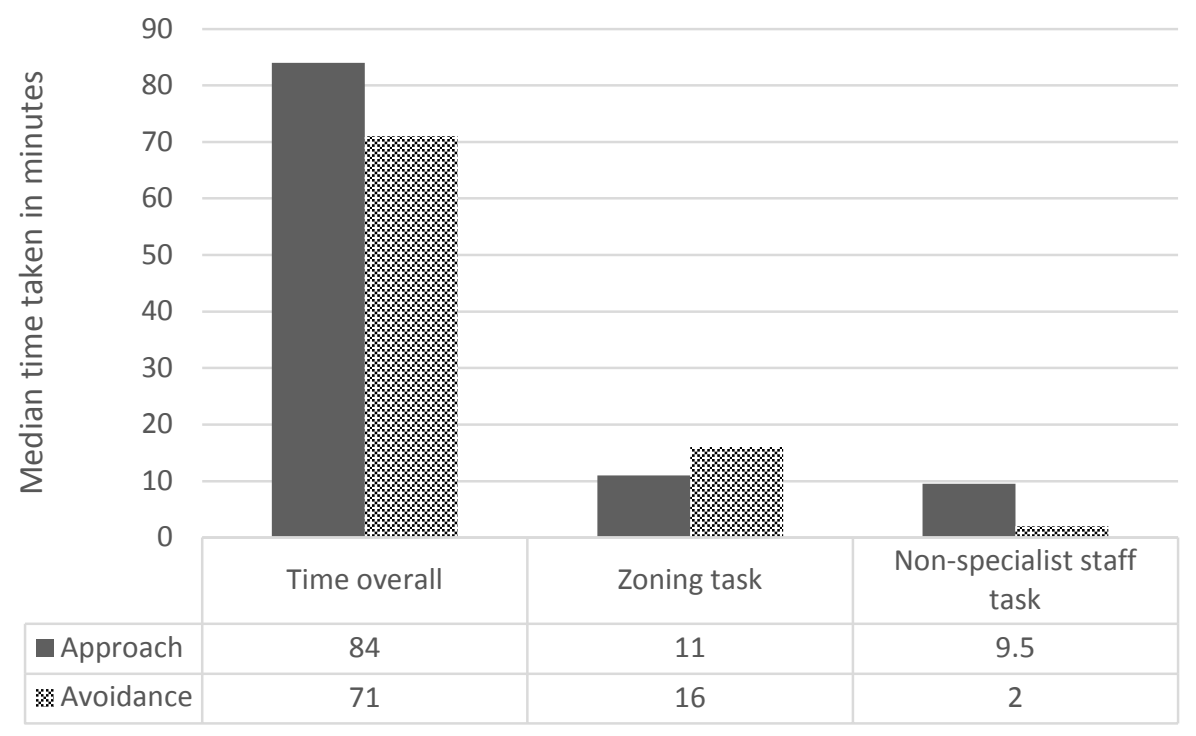

Figure 5: Median response times for attack/approach and defend/avoid teams for: (i) time overall; (ii) time taken to log decision for zoning task; and (iii) time taken to log nonspecialist staff task decision 
Running Head: Approach and avoid goals in emergencies

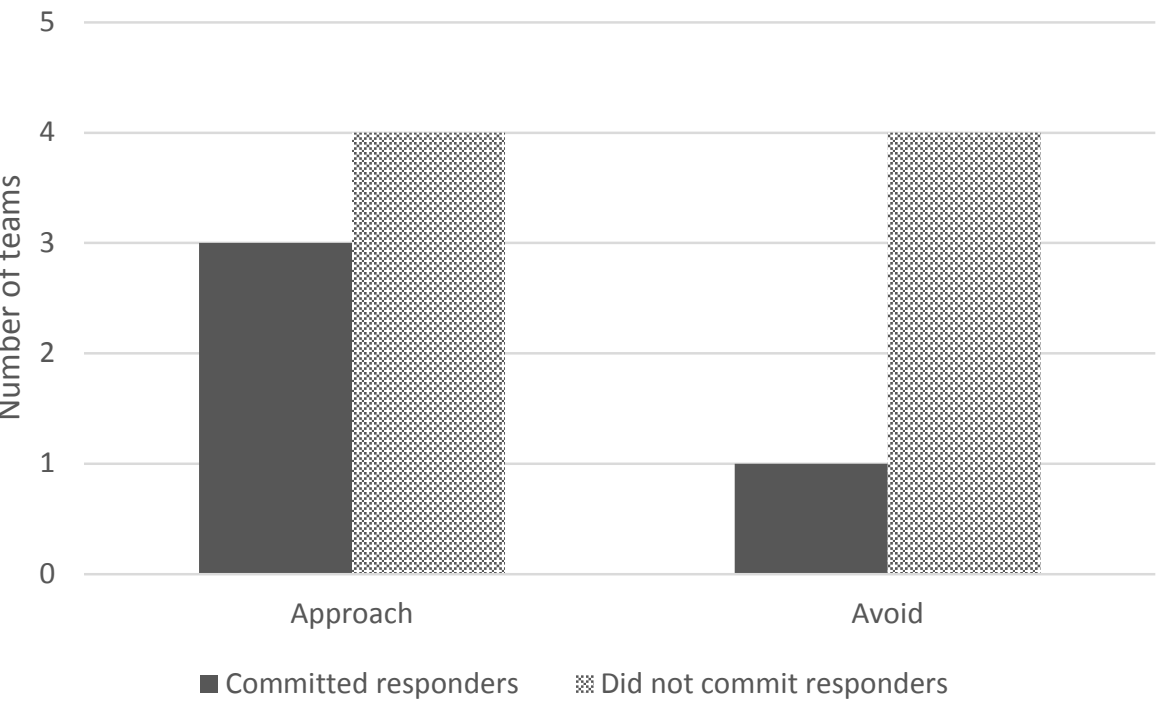

Figure 6: Frequency of teams who chose to commit additional responders to the risk area or not, split according to their attack/approach or defend/avoid goal orientation 


\section{Appendices}

\section{Appendix A: Research protocol for conducting multi-method exploratory research with practitioners}

\begin{tabular}{ll}
\hline $\begin{array}{l}\text { Research } \\
\text { Phase }\end{array}$ & Details \\
\hline $\begin{array}{l}\text { Conception: } \\
\text { Identifying } \\
\text { research and } \\
\text { training needs }\end{array}$ & $\begin{array}{l}\text { An initial meeting was held to identify the individual requirements and common } \\
\text { goals for both researchers and practitioners. For example, training needs in this } \\
\text { study were to complement recent JESIP classroom training by designing a live } \\
\text { multi-team exercise. Research needs included maintaining a level of control over } \\
\text { the scenario by using a linear scenario structure to enable comparison across } \\
\text { groups and to have time for participants to complete the post-scenario } \\
\text { questionnaire. }\end{array}$
\end{tabular}

Development: Scenario development involved agreeing upon the incident context, developing a Scenario and scenario timeline with SMEs, trialling a verbal run through with individuals who measurement were external to scenario development, and adjusting the scenario based on tools feedback. Injects were then recorded and edited. Meanwhile, the research team developed the post-scenario questionnaire and trialled it with SMEs to ensure clarity and add any additional items that may be useful with regards to training.

Testing: Pilot This phase involved a full pilot test of the scenario with independent testing and actual study/training practitioners. Feedback was measured during and after the simulation and changes made accordingly. The final simulation was then built and testing/training commenced.

Feedback: $\quad$ A final important phase was to produce feedback from the testing/training that Practitioner was impactful and useful to both practitioners and academics. A presentation was and academic given to practitioners involved in the study to explain the main findings and a outputs concise practitioner report was produced. Academic output was derived through the writing of this paper.

Note: This table details the methodological approach that was taken to develop the Hydra simulation discussed in this paper. 